\title{
Synthesis and characterization of new fluorene-acceptor alternating and random copolymers for light-emitting applications
}

\author{
Wen-Chung $\mathrm{Wu}^{\text {a }}$, Cheng-Liang Liu ${ }^{\mathrm{a}}$, Wen-Chang Chen ${ }^{\mathrm{a}, \mathrm{b}, *}$ \\ ${ }^{a}$ Department of Chemical Engineering, National Taiwan University, No. 1, Sec. 4, Roosevelt Road, Taipei 106, Taiwan, ROC \\ ${ }^{\mathrm{b}}$ Institute of Polymer Science and Engineering, National Taiwan University, Taipei 106, Taiwan, ROC
}

Received 21 September 2005; received in revised form 17 November 2005; accepted 18 November 2005

Available online 7 December 2005

\begin{abstract}
A series of novel light-emitting copolymers consisted of 9,9-dihexylfluorene (F) and different acceptor segments, including quinoxaline (Q), 2,1,3-benzothiadiazole (BT) and thieno[3,4-b]-pyrazine (TP), were synthesized by the palladium-catalyzed Suzuki coupling reaction. Three fluorene-acceptor alternating copolymers (PFQ, PFBT, PFTP) and six F-TP (PFTP0.5-PFTP35) random copolymers were investigated and compared with the parent polyfluorene (PF). The experimental results suggest that the acceptor strength or content significantly affect the electronic and optoelectronic properties. The optical absorption maxima of the PF, PFQ, PFBT, and PFTP are 368, 416, 470, and 578 nm, respectively, which indicates the significance of intramolecular charge transfer. The electrochemical band gap also shows a similar trend. The incorporation of the acceptor into the PF lowers the LUMO level and thus could improve the electron-accepting ability of the PF. The emission maxima on the photoluminescence (PL) spectra of the PF, PFQ, PFBT, and PFTP films are 424, 493, 540, and 674 nm, which correspond to the color of blue, green, yellow, and red, respectively. It suggests that the full color of emission can be achieved by different acceptors. The significant positive solvatochromism on the PL spectra in different polar solvents suggests the efficient intramolecular charge transfer in PFTP. However, such charge transfer or heavy-atom effect results in fluorescence quenching and thus reduces the PL efficiencies. By random copolymerizing the TP into the PF, the PL efficiency could be improved. A significantly reduction on the PF emission peak with increasing the TP content suggests the energy transfer between the PF and TP segments. Besides, the characteristics on the electroluminescence (EL) devices of ITO/PEDOT:PSS/emissive layer/Ca/Ag suggest that such energy transfer results in the complete quenching of the PF emission at only $1 \%$ TP content in the PFTP01. The maximum external quantum efficiency (EQE) of the EL device based on the PFTP01 is superior to that of the PF due to the reduced LUMO level in matching with the Ca. The CIE 1931 coordinates of the PFTP01 based EL device under the condition of maximum EQE is $(0.66,0.31)$, which is close to the standard red of $(0.66,0.34)$ demanded by the National Television System Committee (NTSC). The luminescence characteristics based on the prepared polymers depend on the Förster energy transfer or the intramolecular charge transfer, or heavy-atom fluorescence quenching. The present study suggests that the tuning of the electronic and optoelectronic properties could be achieved by incorporating various acceptors or content into the polyfluorenes.
\end{abstract}

(C) 2005 Elsevier Ltd. All rights reserved.

Keywords: Polyfluorene; Charge transfer; Luminescence

\section{Introduction}

Conjugated polymers have been extensively studied for their potential applications in electroluminescence displays [1,2], photovoltaic devices [3,4], and thin film transistors [5-7]. They not only combine the physical properties of polymers with those of semiconductors to obtain unique and novel

\footnotetext{
* Corresponding author. Address: Department of Chemical Engineering, National Taiwan University, No. 1, Sec. 4, Roosevelt Road, Taipei 106, Taiwan, ROC. Tel.: +886 2 23628398; fax: +886223623040.

E-mail address: chenwc@ntu.edu.tw (W.-C. Chen).
}

0032-3861/\$ - see front matter (c) 2005 Elsevier Ltd. All rights reserved. doi:10.1016/j.polymer.2005.11.058 materials but also provide tunable electronic and/or mechanical properties by structure modification [8]. The band structures of conjugated polymers can be manipulated by minimization of bond length alternation $[9,10]$ and incorporation of donoracceptor units $[11,12]$, which are key to tune their electronic and optoelectronic properties. We are particularly interested in the donor-acceptor alternating copolymers since their electronic properties are tuned efficiently by intramolecular charge transfer (ICT) [11-14].

Polyfluorenes (PFs) have been widely studied for polymer light-emitting diodes (PLED) because of their processibility, high quantum yield, and good charge transport properties [15]. However, the poor electron-transporting property of polyfluorene results in a large electron-injection barrier and unbalance 


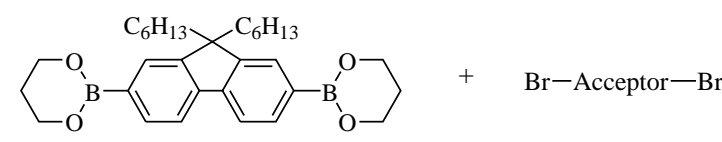

1. $\mathrm{Pd}\left(\mathrm{PPh}_{3}\right)_{4} / \mathrm{K}_{2} \mathrm{CO}_{3}(\mathrm{aq}) /$ Toluene

2. Phenyl boronic acid /Bromobenzene

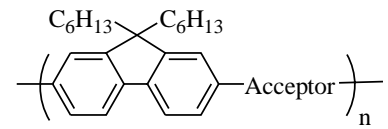

Acceptor $=$

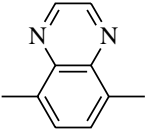

PFQ

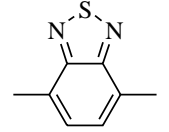

PFBT

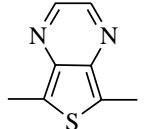

PFTP
Scheme 1. Synthesis of the fluorene-acceptor alternating copolymers, PFQ, PFBT, and PFTP.

of charge carrier transport for the PLED application. Therefore, copolymerization of fluorene with various electron-accepting and/or electron-transporting moieties has been investigated to improve this shortcoming [16]. Recently, donor-acceptor conjugated copolymers based on fluorene with various acceptors were reported in the literature, including benzothiadiazole [16], pyridine [17], bithiazole [18], naphthoselenadiazole [19], indenofluorene [20], quinoxaline [21], and perylene [22]. The light-emitting color or efficiency of PLED based on the fluorene-acceptor copolymers were easily tuned by the acceptors. Besides, photovoltaic devices with good efficiencies were demonstrated by poly $(9,9$-dioctylfluorene-alt-benzothiadiazole) (F8BT) [23]. High electron mobility from the F8BTbased field effect transistor was also reported recently [24].

Although various fluorene based donor-acceptor copolymers have shown tunable optoelectronic properties and promising device applications, the effects of the acceptor strength on the optoelectronic properties have not been addressed yet. In this study, three fluorene-acceptor alternating and six random conjugated copolymers were synthesized using palladium(0)-catalyzed Suzuki coupling reaction and compared, as shown in Schemes 1 and 2, respectively. The physical properties of the synthesized donor-acceptor conjugated polymers were compared with those of the parent poly[2,7-(9,9-dihexylfluorene)] (PF). The studied acceptors included quinoxaline (Q), 2,1,3-benzothiadiazole (BT) and thieno[3,4-b]pyrazine (TP). The LUMO of the Q, BT, and TP are $-0.90,-1.81$, and $-1.41 \mathrm{eV}$, respectively [25], which indicates the order of the acceptor strength is $\mathbf{B T}>\mathbf{T P}>\mathbf{Q}$. Thus, the effects of acceptor strength and intramolecular charge transfer between fluorene and acceptor segments on the optoelectronic properties can be explored. Besides, six fluorene-TP random copolymers were synthesized for investigating the effects of the TP content on the optoelectronic properties. The feeding ratios of the 9,9-dihexylfluorene-2,7bis(trimethyleneborate) and 9,9-dihexyl-2,7-dibromofluorene to the $\mathbf{T P}$ are 99.5:0.5, 99:1, 95:5, 85:15, 75:25, and 65:35 for the random copolymers of PFTP0.5, PFTP01, PFTP05, PFTP15, PFTP25, and PFTP35, respectively. Electroluminescence (EL) devices fabricated from the synthesized polymers as emissive layers were characterized. The possible energy transfer from the fluorene to fluorene-acceptor segment was investigated. The color tuning ability of the EL devices through various acceptors or content was also demonstrated in this study.

\section{Experimental}

\subsection{Materials}

2,1,3-Benzothiadiazole, bromine, glacial acetic acid, zinc dust, glyoxal (40 wt\% in water), 3,4-diaminothiophene dihydrochloride, $\mathrm{N}$-bromosuccinimide, 9,9-dihexylfluorene2,7-bis(trimethyleneborate), 9,9-dihexyl-2,7-dibromofluorene, tetrakis(triphenylphosphine)-palladium(0), potassium carbonate, and trioctylmethylammonium chloride (aliquat ${ }^{\circledR} 336$ ), were purchased from Aldrich (Missouri, USA) or Acros (Geel, Belgium) and used without further purification. Ultra-anhydrous solvents used in the reactions were purchased from Tedia (Ohio, USA). The following acceptor monomers were prepared according to literature procedures: 4,7-dibromo-2,1,3-benzothiadiazole [26], 5,8-dibromoquinoxaline [27,28], and 5,7dibromothieno[3,4-b]-pyrazine $[29,30]$.
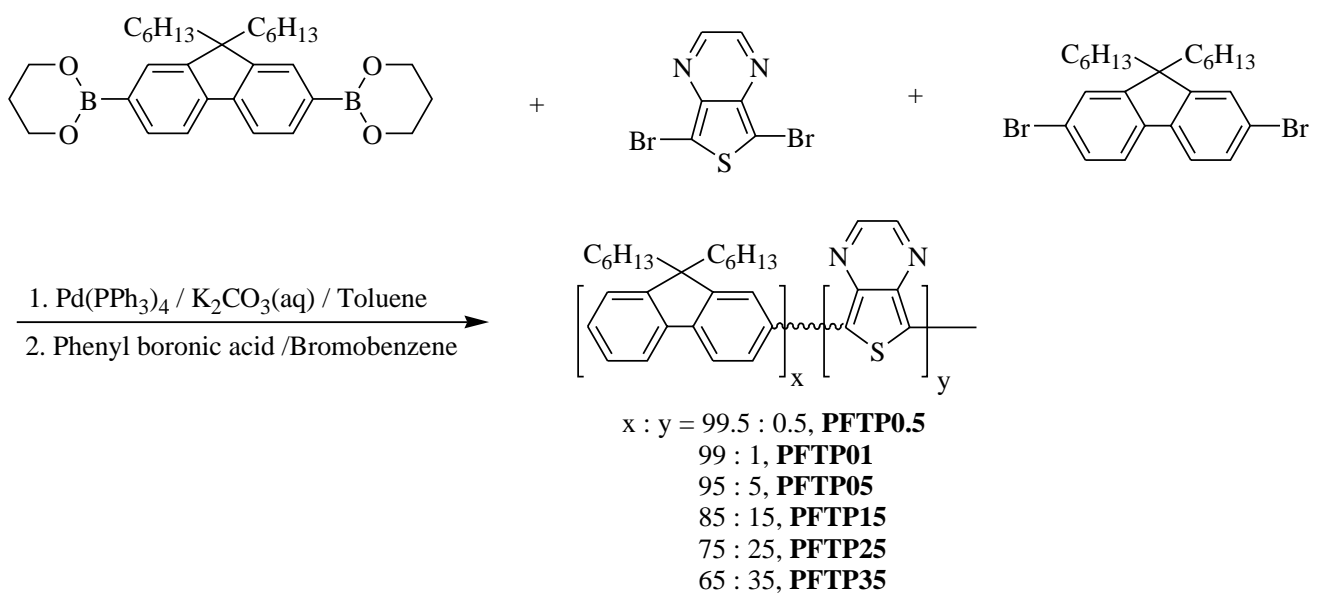

Scheme 2. Synthesis of the fluorene-TP copolymers, PFTP0.5-PFTP35. 


\subsection{General procedure of polymerization}

The general procedure of synthesizing fluorene-acceptor alternating copolymers is shown in Scheme 1. 9,9-Dihexylfluorene-2,7-bis(trimethyleneborate), acceptor monomer ( $\mathbf{Q}$, BT, or TP), tetrakis(triphenylphosphine)palladium(0) (1 mol\% with respect to diborate monomer), and several drops of aliquat $^{\circledR} 336$ were dissolved in toluene. To the reaction mixture, degassed aqueous $2 \mathrm{M} \mathrm{K}_{2} \mathrm{CO}_{3}$ (3.3 equiv. with respect to the diborate monomer) was added. The mixture was refluxed with vigorous stirring for $72 \mathrm{~h}$ under a nitrogen atmosphere. The end groups were capped by refluxing for $12 \mathrm{~h}$ each with phenyl boronic acid and bromobenzene (both 1.1 equiv. with respect to diborate monomer). After endcapping, the mixture was cooled and poured into a mixture of methanol and water. The precipitated material was dissolved into a small amount of THF and then re-precipitated into methanol to afford crude polymer. The crude polymer was washed for $24 \mathrm{~h}$ with acetone to remove oligomers and catalyst residues.

The general procedure of synthesizing fluorene-TP random copolymers is shown in Scheme 2. The same steps were used except for adding different ratios of 9,9-dihexyl-2,7-dibromofluorene and 5,7-dibromothieno[3,4- $b]$ pyrazine instead of 5,7dibromothieno[3,4- $b]$ pyrazine only. The specific polymerization formulation, conditions, and structural characterization are described as below.

\subsubsection{Poly[2,7-(9,9-dihexylfluorene)] (PF)}

$502 \mathrm{mg}$ of 9,9-dihexylfluorene-2,7-bis(trimethyleneborate) (1 mmol), $492 \mathrm{mg}$ of 9,9-dihexyl-2,7-dibromofluorene ( $1 \mathrm{mmol}$ ), and $10 \mathrm{ml}$ of toluene were used to afford $600 \mathrm{mg}$ of light yellow solid (90.3\%). ${ }^{1} \mathrm{H}$ NMR $\left(\mathrm{CDCl}_{3}\right), \delta$ (ppm): 0.80 (br, 10H), 1.15 (br, 12H), 2.15 (br, 4H), 7.68-7.86 (m, br, 6H). ${ }^{13} \mathrm{C} \mathrm{NMR}\left(\mathrm{CDCl}_{3}\right), \delta(\mathrm{ppm}): 14.02,22.56,23.85,29.67,31.46$, 40.36, 55.33, 119.98, 121.52, 126.15, 140.02, 140.53, 151.81. Anal. Calcd for $\mathrm{C}_{25} \mathrm{H}_{32}(\%)$ : C, 90.30; H, 9.70. Found: C, 89.76; H, 9.60.

\subsubsection{Poly[2,7-(9,9'-dihexylfluorene)-alt-5,8-quinoxaline] (PFQ)}

$251 \mathrm{mg}$ of 9,9-dihexylfluorene-2,7-bis(trimethyleneborate) (0.5 mmol), $144 \mathrm{mg}$ of 5,8-dibromoquinoxaline $(0.5 \mathrm{mmol})$, and $5 \mathrm{ml}$ of toluene were used to afford $205 \mathrm{mg}$ of light green solid (88.6\%). ${ }^{1} \mathrm{H} \mathrm{NMR}\left(\mathrm{CDCl}_{3}\right), \delta$ (ppm): 0.81 (br, 6H), 0.95 (br, 4H), 1.19 (br, 12H), 2.10 (br, 4H), 7.71-8.04 (m, br, 8H), 8.93 (br, $2 \mathrm{H}) .{ }^{13} \mathrm{C} \mathrm{NMR}\left(\mathrm{CDCl}_{3}\right), \delta$ (ppm): 14.07, 22.68, 24.20, 29.90, 31.58, 40.14, 55.22, 119.56, 125.65, 129.63, 130.23, 137.15, 140.38, 140.77, 141.43, 144.18, 151.21. Anal. Calcd for $\mathrm{C}_{33} \mathrm{H}_{36} \mathrm{~N}_{2}(\%)$ : C, 86.04; H, 7.88; N, 6.08. Found: C, 85.17; $\mathrm{H}, 7.81 ; \mathrm{N}, 5.92$.

\subsubsection{Poly[2,7-(9,9'-dihexylfluorene)-alt-4,7-(2,1,3-benzo- thiadiazole)] (PFBT)}

$502 \mathrm{mg}$ of 9,9-dihexylfluorene-2,7-bis(trimethyleneborate) (1 mmol), $294 \mathrm{mg}$ of 4,7-dibromo-2,1,3-benzothiadiazole ( $1 \mathrm{mmol})$, and $10 \mathrm{ml}$ of toluene were used to afford $420 \mathrm{mg}$ of yellow solid (89.6\%). ${ }^{1} \mathrm{H}$ NMR $\left(\mathrm{CDCl}_{3}\right), \delta$ (ppm): 0.80 (br, 6H), 0.96 (br, 4H), 1.17 (br, 12H), 2.15 (br, 4H), 7.74-8.11 (m, br, 8H). ${ }^{13} \mathrm{C} \mathrm{NMR}\left(\mathrm{CDCl}_{3}\right), \delta$ (ppm): 14.06, 22.61, 24.03, $29.80,31.52,40.25,55.43,120.05,124.04,127.98,133.62$, $136.47,140.86,151.77,154.37$. The peak positions of the NMR spectra are similar to that reported in the literature [12a]. Anal. Calcd for $\mathrm{C}_{31} \mathrm{H}_{34} \mathrm{~N}_{2} \mathrm{~S}(\%)$ : C, 79.79; H, 7.34; N, 6.00; S, 6.87. Found: C, 78.55; H, 7.39; N, 5.85; S, 6.58.

\subsubsection{Poly[2,7-(9,9'-dihexylfluorene)-alt-5,7-(thieno[3,4-b] pyrazine)] (PFTP)}

$502 \mathrm{mg}$ of 9,9-dihexylfluorene-2,7-bis(trimethyleneborate) (1 mmol), $294 \mathrm{mg}$ of 5,7-dibromothieno[3,4-b]pyrazine ( $1 \mathrm{mmol})$, and $10 \mathrm{ml}$ of toluene were used to afford $340 \mathrm{mg}$ of deep purple solid (72.5\%). ${ }^{1} \mathrm{H}$ NMR $\left(\mathrm{CDCl}_{3}\right), \delta$ (ppm): 0.79 (br, 6H), 0.89 (br, 4H), 1.15 (br, 12H), 2.19 (br, 4H), 7.85-8.35 $(\mathrm{m}, \mathrm{br}, 6 \mathrm{H}), 8.60(\mathrm{~m}, \mathrm{br}, 2 \mathrm{H}) .{ }^{13} \mathrm{C} \mathrm{NMR}\left(\mathrm{CDCl}_{3}\right), \delta(\mathrm{ppm})$ : 14.07, 22.57, 23.89, 29.72, 31.48, 40.51, 55.22, 120.39, 122.43, 127.30, 132.15, 132.80, 140.41, 140.62, 144.10, 151.97. Anal. Calcd for $\mathrm{C}_{31} \mathrm{H}_{34} \mathrm{~N}_{2} \mathrm{~S}(\%)$ : C, 79.78; H, 7.34; N, 6.00; S, 6.87. Found: C, 78.57; H, 7.52; N, 5.82; S, 6.37.

\subsubsection{Poly[2,7-(9,9'-dihexylfluorene)-alt-5,7-(thieno[3,4-b] pyrazine)] (PFTP0.5)}

$502 \mathrm{mg}$ of 9,9-dihexylfluorene-2,7-bis(trimethyleneborate) (1 mmol), $2.9 \mathrm{mg}$ of 5,7-dibromothieno[3,4-b]pyrazine (0.01 mmol), $487.4 \mathrm{mg}$ of 9,9-dihexyl-2,7-dibromofluorene $(0.99 \mathrm{mmol})$, and $10 \mathrm{ml}$ of toluene were used to afford $565 \mathrm{mg}$ of red solid. ${ }^{1} \mathrm{H} \mathrm{NMR}\left(\mathrm{CDCl}_{3}\right), \delta$ (ppm): 0.79 (br, 10H), 1.14 (br, 12H), 2.13 (br, 4H), 7.68-7.86 (m, br, 6H). ${ }^{13} \mathrm{C}$ NMR $\left(\mathrm{CDCl}_{3}\right), \delta$ (ppm): 14.02, 22.56, 23.84, 29.67, 31.46, 40.35, 55.33, 119.97, 121.52, 126.15, 140.00, 140.53, 151.81. Anal. Calcd for $\mathrm{C}_{24.905} \mathrm{H}_{31.85} \mathrm{~N}_{0.01} \mathrm{~S}_{0.005}(\%)$ : C, 90.23; H, 9.68; N, 0.04; S, 0.05. Found: C, 89.07; H, 9.32; N, 0.03; S, 0.04 .

\subsubsection{Poly[2,7-(9,9'-dihexylfluorene)-alt-5,7-(thieno[3,4-b] pyrazine)] (PFTP01)}

$502 \mathrm{mg}$ of 9,9-dihexylfluorene-2,7-bis(trimethyleneborate) (1 mmol), $5.9 \mathrm{mg}$ of 5,7-dibromothieno[3,4-b]pyrazine (0.02 mmol), $482.5 \mathrm{mg}$ of 9,9-dihexyl-2,7-dibromofluorene $(0.98 \mathrm{mmol})$, and $10 \mathrm{ml}$ of toluene were used to afford $570 \mathrm{mg}$ of red solid. ${ }^{1} \mathrm{H}$ NMR $\left(\mathrm{CDCl}_{3}\right), \delta$ (ppm): 0.80 (br, $\left.10 \mathrm{H}\right), 1.15$ (br, 12H), 2.13 (br, 4H), 7.68-7.86 (m, br, 6H). ${ }^{13} \mathrm{C}$ NMR $\left(\mathrm{CDCl}_{3}\right), \delta$ (ppm): 14.02, 22.56, 23.85, 29.67, 31.46, 40.36, 55.33, 119.97, 121.52, 126.16, 140.02, 140.53, 151.81. Anal. Calcd for $\mathrm{C}_{24.81} \mathrm{H}_{31.7} \mathrm{~N}_{0.02} \mathrm{~S}_{0.01}(\%)$ : C, 90.15; H, 9.67; N, 0.08; S, 0.10. Found: C, 89.31; H, 10.03; N, 0.09; S, 0.11.

\subsubsection{Poly[2,7-(9,9'-dihexylfluorene)-alt-5,7-(thieno[3,4-b] pyrazine)] (PFTP05)}

$502 \mathrm{mg}$ of 9,9-dihexylfluorene-2,7-bis(trimethyleneborate) (1 mmol), $29.4 \mathrm{mg}$ of 5,7-dibromothieno[3,4-b]pyrazine (0.1 mmol), $443 \mathrm{mg}$ of 9,9-dihexyl-2,7-dibromofluorene $(0.9 \mathrm{mmol})$, and $10 \mathrm{ml}$ of toluene were used to afford $550 \mathrm{mg}$ of purple-red solid. ${ }^{1} \mathrm{H}$ NMR $\left(\mathrm{CDCl}_{3}\right), \delta(\mathrm{ppm})$ : $0.80(\mathrm{br}, 10 \mathrm{H})$, 1.14 (br, 12H), 2.13 (br, 4H), 7.68-8.32 (m, br, 6H), 8.63 $(\mathrm{m}, \mathrm{br}, 0.096 \mathrm{H}) .{ }^{13} \mathrm{C} \mathrm{NMR}\left(\mathrm{CDCl}_{3}\right), \delta(\mathrm{ppm}): 14.02,22.55$, $23.84,29.66,31.45,40.35,55.32,119.97,121.58,126.15$, 
$140.00,140.51,141.35,144.23,151.80$. Anal. Calcd for $\mathrm{C}_{24.05} \mathrm{H}_{30.5} \mathrm{~N}_{0.1} \mathrm{~S}_{0.05}(\%)$ : C, 89.54; H, 9.53; N, 0.43; S, 0.50. Found: C, 88.86; H, 9.09; N, 0.22; S, 0.44.

\subsubsection{Poly[2,7-(9,9'-dihexylfluorene)-alt-5,7-(thieno[3,4-b] pyrazine)] (PFTP15)}

$502 \mathrm{mg}$ of 9,9-dihexylfluorene-2,7-bis(trimethyleneborate) (1 mmol), $88 \mathrm{mg}$ of 5,7-dibromothieno[3,4-b]pyrazine $(0.3 \mathrm{mmol}), 345 \mathrm{mg}$ of 9,9-dihexyl-2,7-dibromofluorene $(0.7 \mathrm{mmol})$, and $10 \mathrm{ml}$ of toluene were used to afford $490 \mathrm{mg}$ of purple-red solid. ${ }^{1} \mathrm{H}$ NMR $\left(\mathrm{CDCl}_{3}\right), \delta$ (ppm): 0.79 (br, $\left.10 \mathrm{H}\right)$, 1.14 (br, 12H), 2.13 (br, 4H), 7.80-8.33 (m, br, 6H), 8.61 $(\mathrm{m}$, br, $0.328 \mathrm{H}) .{ }^{13} \mathrm{C} \mathrm{NMR}\left(\mathrm{CDCl}_{3}\right), \delta(\mathrm{ppm}): 14.02,22.55$, $23.85,29.66,31.45,40.35,55.44,119.97,121.52,126.16$, 140.01, 140.52, 141.62, 144.38, 151.81. Anal. Calcd for $\mathrm{C}_{22.15} \mathrm{H}_{27.5} \mathrm{~N}_{0.3} \mathrm{~S}_{0.15}(\%)$ : C, 87.87; H, 9.16; N, 1.39; S, 1.59. Found: C, 88.19; H, 8.95; N, 0.82; S, 1.30.

\subsubsection{Poly[2,7-(9,9'-dihexylfluorene)-alt-5,7-(thieno[3,4-b] pyrazine)] (PFTP25)}

$502 \mathrm{mg}$ of 9,9-dihexylfluorene-2,7-bis(trimethyleneborate) (1 mmol), $147 \mathrm{mg}$ of 5,7-dibromothieno[3,4-b]pyrazine (0.5 mmol), $246 \mathrm{mg}$ of 9,9-dihexyl-2,7-dibromofluorene $(0.5 \mathrm{mmol})$, and $10 \mathrm{ml}$ of toluene were used to afford $450 \mathrm{mg}$ of deep purple solid. ${ }^{1} \mathrm{H}$ NMR $\left(\mathrm{CDCl}_{3}\right), \delta$ (ppm): 0.80 (br, 10H), 1.16 (br, 12H), 2.14 (br, 4H), 7.70-8.34 $(\mathrm{m}$, br, $6 \mathrm{H}), 8.61(\mathrm{~m}, \mathrm{br}, 0.627 \mathrm{H}) .{ }^{13} \mathrm{C} \mathrm{NMR}\left(\mathrm{CDCl}_{3}\right), \delta$ (ppm): 14.02, 22.55, 23.84, 29.66, 31.46, 40.34, 55.38, 119.98, 121.52, 122.49, 126.17, 140.52, 141.21, 144.07, 151.84. Anal. Calcd for $\mathrm{C}_{20.25} \mathrm{H}_{24.5} \mathrm{~N}_{0.5} \mathrm{~S}_{0.25}$ (\%): C, 85.97; H, 8.73; N, 2.47; S, 2.83. Found: C, 85.93; H, 8.77; N, 1.74; S, 2.75.

\subsubsection{Poly[2,7-(9,9'-dihexylfluorene)-alt-5,7-(thieno[3,4-b] pyrazine)] (PFTP35)}

$502 \mathrm{mg}$ of 9,9-dihexylfluorene-2,7-bis(trimethyleneborate) (1 mmol), $206 \mathrm{mg}$ of 5,7-dibromothieno[3,4-b]pyrazine (0.7 mmol), $148 \mathrm{mg}$ of 9,9-dihexyl-2,7-dibromofluorene $(0.3 \mathrm{mmol})$, and $10 \mathrm{ml}$ of toluene were used to afford $380 \mathrm{mg}$ of deep purple solid. ${ }^{1} \mathrm{H}$ NMR $\left(\mathrm{CDCl}_{3}\right), \delta$ (ppm): 0.82 (br, 10H), 1.25 (br, 12H), 2.36 (br, 4H), 7.83-8.35 (m, br, 6H), 8.60 (m, br, 1.111H). ${ }^{13} \mathrm{C} \mathrm{NMR}\left(\mathrm{CDCl}_{3}\right), \delta$ (ppm): 14.00, 22.57, 23.73, 29.67, 31.48, 40.31, 55.45, 120.18, 121.44, 122.46, 132.45, 140.44, 142.34, 144.10, 151.82. Anal. Calcd for $\mathrm{C}_{18.35} \mathrm{H}_{21.5} \mathrm{~N}_{0.70} \mathrm{~S}_{0.35}(\%)$ : C, 83.77; H, 8.24; N, 3.73; S, 4.26.Found: C, 83.21; H, 8.05; N, 3.65; S, 4.36.

\subsection{Characterization}

${ }^{1} \mathrm{H}$ and ${ }^{13} \mathrm{C}$ nuclear magnetic resonance (NMR) data were obtained by a Bruker AV $500 \mathrm{MHz}$ spectrometer. Gel permeation chromatographic analysis was performed on a Lab Alliance RI2000 instrument (two column, MIXED-C and D from Polymer Laboratories) connected with one refractive index detector from Schambeck SFD Gmbh. All GPC analyses were performed on polymer/THF solution at a flow rate of $1 \mathrm{ml} / \mathrm{min}$ at $40{ }^{\circ} \mathrm{C}$ and calibrated with polystyrene standards.
Thermogravimetric analysis (TGA) and differential scanning calorimetry (DSC) measurements were performed under a nitrogen atmosphere at a heating rate of 20 and $10^{\circ} \mathrm{C} / \mathrm{min}$ using a TA instrument TGA-951 and DSC-910S, respectively. UV-visible absorption and photoluminescence (PL) spectra were recorded on a Jasco model UV/VIS/NIR V-570 spectrometer and Fluorolog-3 spectrofluorometer (Jobin Yvon), respectively. For the solution spectra, polymers were dissolved in THF (ca. $10^{-6} \mathrm{M}$ ) and then put in a quartz cell for measurement. For the thin film spectra, polymers were first dissolved in THF $(1 \mathrm{wt} \%)$ and then spin-coated on glass substrate at $1000 \mathrm{rpm}$ for $30 \mathrm{~s}$. Then, the thin film samples were dried at $60{ }^{\circ} \mathrm{C}$ under vacuum for measurement. Films used for the PL efficiency measurement were drop-coated from THF solution onto quartz substrates (ca. $1 \mathrm{wt} \%$ ). PL efficiencies of polymer films on quartz substrates were measured using fluorolog 3 in combination with integrating sphere with $380 \mathrm{~nm}$ excitation.

The electrochemical properties of the polymer films were investigated on a Princeton Applied Research Model 273A Potentiostat/Galvanostat with a $0.1 \mathrm{M}$ acetonitrile $(99.5+\%$, Tedia) solution containing tetrabutylammonium tetrafluoroborate $\left(\mathrm{TBABF}_{4}\right)($ Fluka, $>99.9 \%)$ as the electrolyte. Platinum wire and rod-tip electrodes were used as counter and working electrodes respectively. Silver/silver ion (Ag in $0.1 \mathrm{M} \mathrm{AgNO}_{3}$ (Acros, 99.8\%) in the supporting electrolyte solutions) was used as a reference electrode. A $3 \mathrm{wt} \%$ solution of a polymer in THF or DMSO was used to prepare the polymer film on the $\mathrm{Pt}$ rod-tip electrode. Then, the cyclic voltammetry of films was performed on a three-electrode cell. The reference electrode was calibrated through by the cyclic voltammetry of ferrocene without any polymer added into the solution. The cyclic voltammograms were obtained at a voltage scan rate of $50 \mathrm{mV} / \mathrm{s}$. The potential values obtained versus $\mathrm{Fc}^{+} / \mathrm{Fc}$ standard were converted to the saturated calomel electrode (SCE) scale by adding a constant voltage to them. The energy parameters EA and IP were estimated from the measured redox potentials on the basis of the prior work on conjugated polymers which has shown that: $\mathrm{IP}=\left(E_{\text {onset }}^{\text {ox }}+4.4\right)$ and $\mathrm{EA}=\left(E_{\text {onset }}^{\text {red }}+4.4\right)$, where the onset potentials are in volts (vs. SCE) and IP and EA are in electron volts. The $4.4 \mathrm{eV}$ constant in the relation among IP, EA, and redox potentials is the SCE energy level versus vacuum $[13,31]$. The electronic structure parameters, HOMO and LUMO, were estimated with the relation of $\mathrm{HOMO}=-\mathrm{IP}$ and $\mathrm{LUMO}=-\mathrm{EA}$ by assuming no configuration interactions.

\subsection{Device fabrication and testing}

The electroluminescent (EL) devices were fabricated on indium-tin oxide (ITO) coated glass substrate with sheet resistance of $20-30 \Omega / s q$. The substrate was ultrasonically cleaned with detergent, deionized water, acetone, and methanol, subsequently. Onto the ITO glass a layer of poly(ethylene dioxythiophene):poly(styrene sulfonate) (PEDOT:PSS), 50-60 nm thick (probed by Alpha-Step ${ }^{\circledR} 500$ Surface Profiler), was formed by spin-coated from its aqueous 
solution (Baytron P 8000, Bayer). The emissive layer was spincoated at $1500 \mathrm{rpm}$ from the corresponding p-xylene solution $(1.5 \mathrm{wt} \%)$ on top of the vacuum-dried PEDOT:PSS layer. The nominal thickness of the emissive layer was 60-70 nm. Under a base pressure below $2 \times 10^{-4}$ Torr, a layer of $\mathrm{Ca}(10 \mathrm{~nm})$ was vacuum deposited as cathode and a thick layer of $\mathrm{Ag}(100 \mathrm{~nm})$ was deposited subsequently as the protecting layer. The cathode area defines the active area of the device, which is $0.1256 \mathrm{~cm}^{2}$ in this study.

Current-voltage characteristics were measured with a computerized Keithley 2400 source measure unit. The luminance and CIE coordinate of device were measured with KonicaMinolta Chroma Meter CS-100A. The EL spectrum of device was recorded on Fluorolog-3 spectrofluorometer (Jobin Yvon).

\section{Results and discussions}

\subsection{Structural characterization of fluorene-based donor-acceptor copolymers}

Fig. 1(a) and (b) shows the ${ }^{1} \mathrm{H}$ NMR spectra of PFQ and PFTP in $\mathrm{CDCl}_{3}$, respectively. The signals in the ranges of

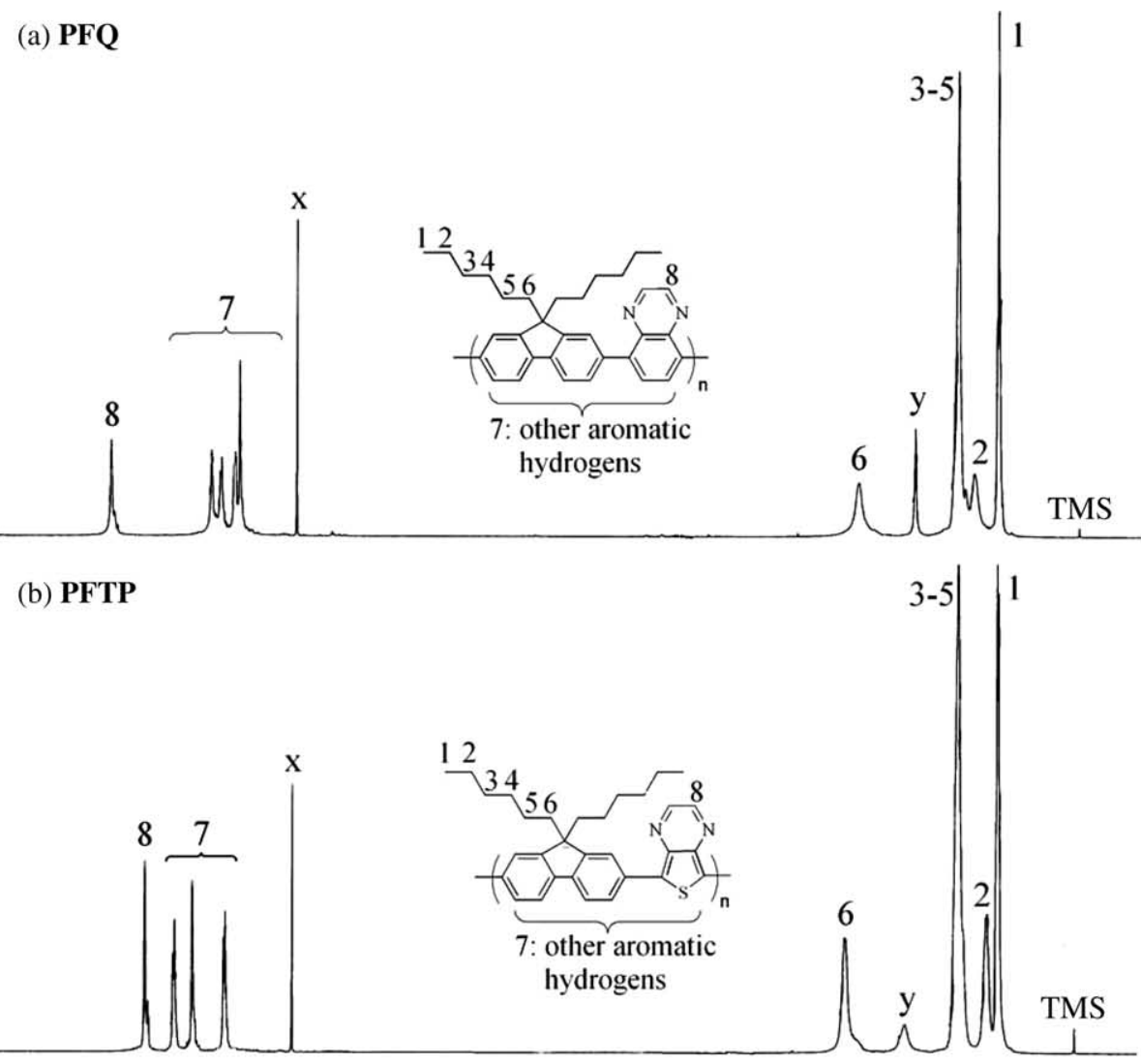

(c) PFTP25

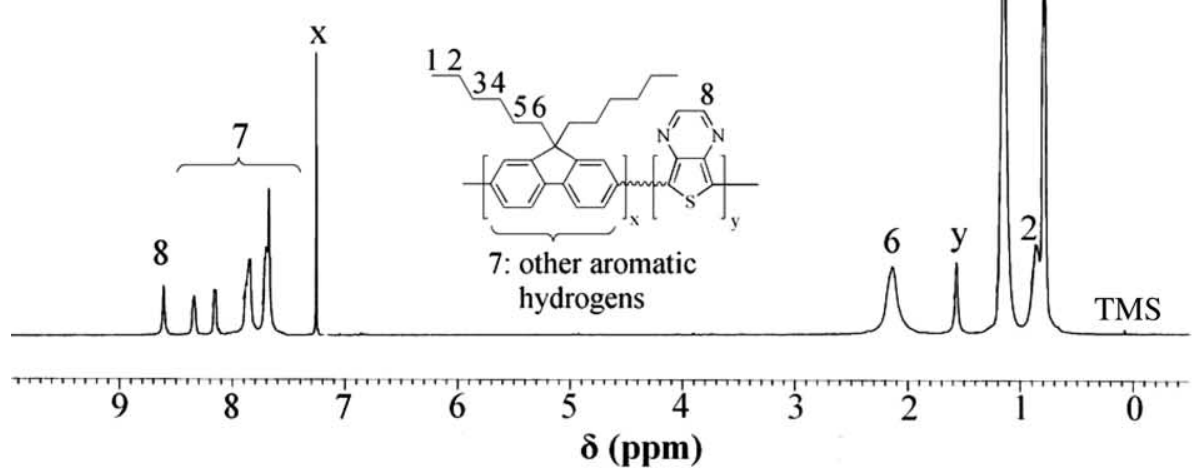

Fig. 1. ${ }^{1} \mathrm{H}$ NMR spectrum of the (a) PFQ; (b) PFTP; (c) PFTP25 in $\mathrm{CDCl}_{3}$, in which labels of $\mathrm{x}$ and $\mathrm{y}$ are $\mathrm{CHCl}_{3}$ and $\mathrm{H}_{2} \mathrm{O}$, respectively. 
Table 1

Molecular weights and thermal properties of the studied polymers

\begin{tabular}{|c|c|c|c|c|c|c|}
\hline & \multirow[t]{2}{*}{$M_{\mathrm{n}}\left(\times 10^{3}\right)$} & \multirow[t]{2}{*}{ PDI } & \multirow[t]{2}{*}{$T_{\mathrm{g}}\left({ }^{\circ} \mathrm{C}\right)$} & \multirow[t]{2}{*}{$T_{\mathrm{d}}\left({ }^{\circ} \mathrm{C}\right)^{\mathrm{a}}$} & \multicolumn{2}{|c|}{ Acceptor ratio $(\%)$} \\
\hline & & & & & Theoretical & Exp. $^{b}$ \\
\hline PF & 57 & 3.41 & 67 & 409 & 0 & 0 \\
\hline PFQ & 19 & 1.87 & 132 & 446 & 50 & 49.1 \\
\hline PFBT & 19 & 2.10 & 115 & 434 & 50 & 48.5 \\
\hline PFTP & 9 & 1.47 & 160 & 447 & 50 & 47.4 \\
\hline PFTP0.5 & 40 & 3.03 & 105 & 432 & 0.5 & 0.4 \\
\hline PFTP01 & 37 & 2.95 & 104 & 434 & 1 & 1.1 \\
\hline PFTP05 & 33 & 2.56 & 108 & 442 & 5 & 4.4 \\
\hline PFTP15 & 31 & 2.48 & 113 & 446 & 15 & 13.9 \\
\hline PFTP25 & 25 & 2.03 & 130 & 445 & 25 & 24.4 \\
\hline PFTP35 & 11 & 1.52 & 137 & 446 & 35 & 35.6 \\
\hline
\end{tabular}

a $95 \mathrm{wt} \%$ residue temperature.

b Estimated from results of elemental analysis.

0.79-2.19 and 7.71-8.04 ppm are assigned to the hexyl and phenylene protons, respectively. The signals assigned to protons on the $\mathbf{Q}$ and $\mathbf{T P}$ segments are around 8.93 and $8.60 \mathrm{ppm}$, respectively. The numbers of protons estimated from the integration of peaks are in good agreement with the proposed structures. The ${ }^{13} \mathrm{C}$ NMR results also support the proposed chemical structures of PFQ and PFTP. Fig. 1(c) shows the ${ }^{1} \mathrm{H}$ NMR spectrum of PFTP25 in $\mathrm{CDCl}_{3}$. The signals assigned to the phenylene protons at 7.70-8.34 ppm split into four peaks instead of three peaks in Fig. 1(b), which could be attributed to the random arrangement of fluorene and TP segments on the backbone. The actual content of the TP segments on the backbone was estimated based on the $\mathrm{N}$ and $\mathrm{S}$ contents obtained in the elemental analysis, which are listed in Table 1. As shown in the table, the theoretical and experimental acceptor contents are in a good agreement.

The resulted copolymers (PFQ, PFBT, PFTP, and PFTP0.5-PFTP35) are readily soluble in $\mathrm{CHCl}_{3}, \mathrm{THF}$, and toluene. The molecular weights of these copolymers are listed in Table 1. The number-averaged molecular weights

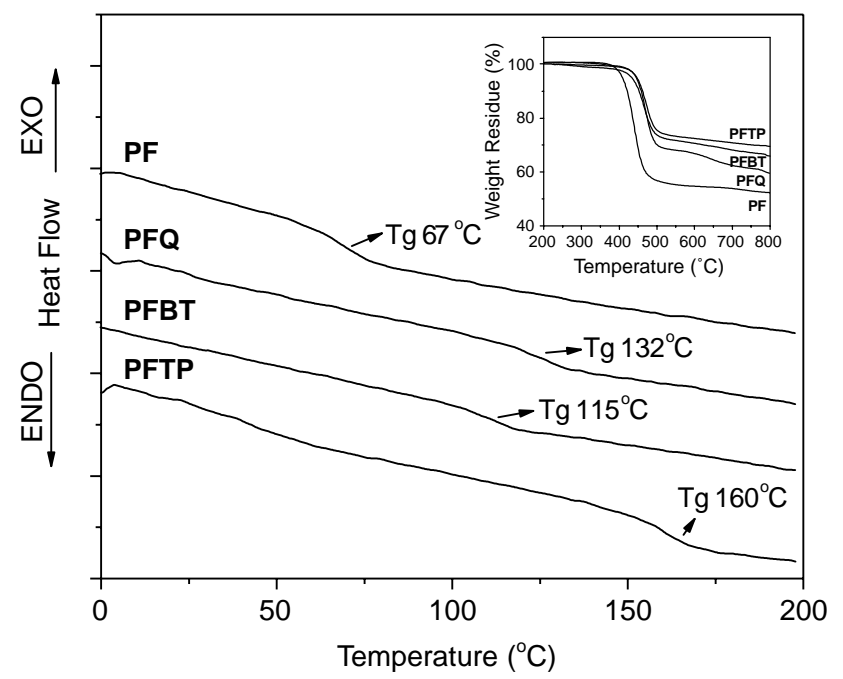

Fig. 2. DSC curves of the PF, PFQ, PFBT, and PFTP at a heating rate of $10^{\circ} \mathrm{C} / \mathrm{min}$ under a nitrogen atmosphere. The insert shows the TGA curves of the above polymers at a heating rate of $20^{\circ} \mathrm{C} / \mathrm{min}$ under a nitrogen atmosphere. and polydispersity indices $\left(M_{\mathrm{n}}, \mathrm{PDI}\right)$ of the PFQ, PFBT, and PFTP are (18970, 1.87), (19229, 2.10), and (8900, 1.47), respectively. The $M_{\mathrm{n}}$ of the PFTP0.5-PFTP35 decreases with increasing the $\mathbf{T P}$ content, which could be attributed to poor solubility or reactivity of the TP monomers in toluene. The experimental carbon, hydrogen, and nitrogen content of the synthesized polymers are in a good agreement with the theoretical values, which indicates the successful preparation of the proposed polymers.

\subsection{Thermal properties}

Fig. 2 shows the TGA (insert figure) and DSC curves of the PF, PFQ, PFBT, and PFTP, respectively. The thermal decomposition temperatures $\left(T_{\mathrm{d}}, 95 \mathrm{wt} \%\right.$ residue $)$ and glass transition temperatures $\left(T_{\mathrm{g}}\right)$ estimated from their TGA and DSC curves are summarized in Table 1, respectively. The $T_{\mathrm{d}}$ of the PFQ, PFBT, and PFTP are 446, 434, and $447^{\circ} \mathrm{C}$, respectively, which are higher than that of the parent $\mathbf{P F}$ with $409^{\circ} \mathrm{C}$. As shown in Fig. 2, the $T_{\mathrm{g}}$ of the PF, PFQ, PFBT, and PFTP are $67,132,115$, and $160{ }^{\circ} \mathrm{C}$, respectively. The $T_{\mathrm{g}}$ of

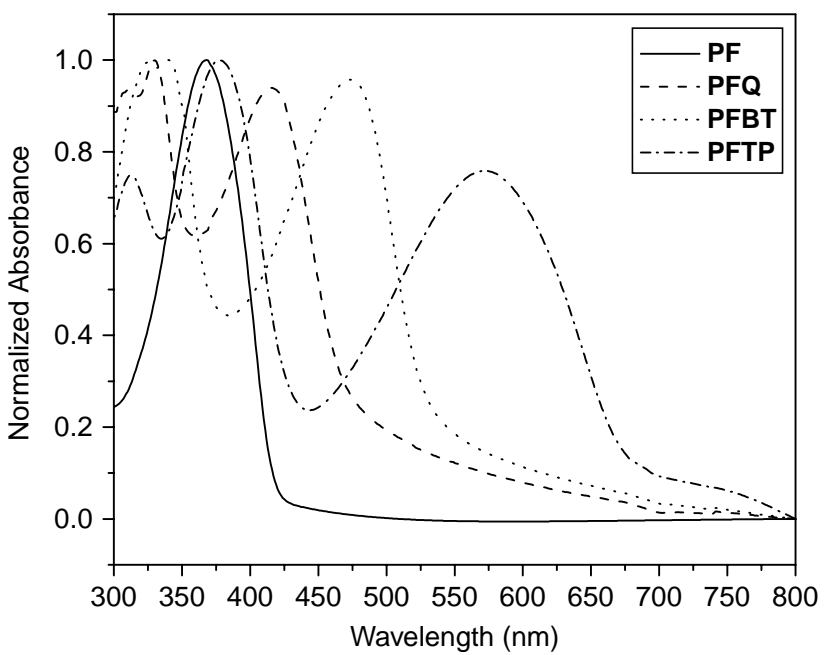

Fig. 3. Normalized UV-vis absorption spectra of the PF, PFQ, PFBT, and PFTP films. 
Table 2

Optical properties of the studied polymers

\begin{tabular}{|c|c|c|c|c|c|}
\hline & $\lambda_{\max }^{\mathrm{abs}}($ film $)(\mathrm{nm})$ & $E_{\mathrm{g}}^{\mathrm{opt}}(\mathrm{eV})^{\mathrm{a}}$ & $\lambda_{\max }^{\mathrm{PL}}\left(\operatorname{soln}^{\mathrm{b}}\right)(\mathrm{nm})$ & $\lambda_{\max }^{\mathrm{PL}}($ film $)(\mathrm{nm})$ & $\Psi^{\mathrm{PL}}(\%)$ \\
\hline PF & 368 & 2.95 & 412,437 & 424,445 , & 56.6 \\
\hline PFQ & 416 & 2.64 & 488 & 493 & 22.4 \\
\hline PFBT & 470 & 2.34 & 532 & 540 & 18.5 \\
\hline PFTP & 378,578 & 1.82 & 646 & $439,508,674$ & 2.1 \\
\hline PFTP0.5 & 381 & 2.95 & 415,440 & $425,446,620$ & 37.3 \\
\hline PFTP01 & 382 & 2.02 & 415,440 & $425,446,629,655$ & 25.3 \\
\hline PFTP05 & 381,530 & 1.98 & $414,440,634$ & $449,474,635,655$ & 11.3 \\
\hline PFTP15 & 382,540 & 1.94 & $414,439,636$ & $450,640,654$ & 6.9 \\
\hline PFTP25 & 381,551 & 1.90 & $416,439,640$ & 659 & 5.1 \\
\hline PFTP35 & 382,578 & 1.82 & $416,440,642$ & $439,510,669$ & 3.7 \\
\hline
\end{tabular}

a Estimated from the absorption edge of the thin film.

${ }^{\mathrm{b}}$ In THF dilute solution (ca. $10^{-6} \mathrm{M}$ ).

the fluorene-TP copolymers increases with increasing the TP content from the $105{ }^{\circ} \mathrm{C}$ of PFTP0.5 to $137^{\circ} \mathrm{C}$ of PFTP35. It suggests that the thermal properties of the $\mathbf{P F}$ can be elevated by incorporating the acceptor moiety on the backbone, which might be important for device applications.

\subsection{Optical absorption and electrochemical characteristics}

The UV-visible absorption spectra of the PF, PFQ, PFBT, and PFTP films are shown in Fig. 3, and the corresponding absorption maximum $\left(\lambda_{\max }\right)$ are summarized in Table 2 . The $\lambda_{\max }$ of the PF, PFQ, PFBT, and PFTP films are 368, 416, 470 , and $578 \mathrm{~nm}$, respectively. It suggests that the optical properties of these polymers could be tuned over a wide range through different acceptors. The optical band gaps $(\mathrm{eV})$ estimated from the absorption edges are in the order of PF (2.95) $>$ PFQ (2.64) > PFBT (2.34) > PFTP (1.82). Note that the optical band gap of the PFBT is in a good agreement with that of $2.40 \mathrm{eV}$ reported in literature [32]. The much lower band gaps of the PFQ, PFBT, and PFTP than that of the parent PF are probably due to the intramolecular charge transfer between the fluorene and acceptor or the backbone planarity. However, the decrement of band gaps of these alternating copolymers is not in consistence with the increasing order of the acceptor strength. As described in the introduction section, the electron-accepting strength is in the order of $\mathbf{B T}>\mathbf{T P}>\mathbf{Q}$ [25]. The smaller band gap of the PFTP than that of the PFBT might be because of the backbone planarity. The TP with the five member thiophene ring results in a smaller torsional angle with fluorene than that of the BT with the six-member phenylene ring, which assists the efficient intramolecular charge transfer and results in a smaller band gap. The extended tails and/or shoulders near the absorption edges of PFQ, PFBT, and PFTP suggest stronger inter-chain interaction as compared to the parent PF. This could also result in a smaller band gap.

The UV-visible absorption spectra of the PF, PFTP, and PFTP0.5-PFTP35 films are shown in Fig. 4, and the corresponding $\lambda_{\max }$ are summarized in Table 2. Two absorption peaks are observed in the absorption spectra of the copolymers. The short-wavelength absorption peaks around $380 \mathrm{~nm}$ could be attributed to the PF segment as compared to that of the PF. The $\lambda_{\max }(519-578 \mathrm{~nm})$ and intensities of the long-wavelength absorption peaks increase with increasing the TP content, implying that this band is probably attributed to the TP segment. As the TP content increases, the extender tails and/or shoulders near the absorption edges become more obvious, suggesting the extent of inter-chain interaction increasing with acceptor content on the backbone.

The oxidation and reduction potentials of these polymers were investigated by cyclic voltammetry. Fig. 5 represents the cyclic voltammograms of the PF, PFQ, PFBT, and PFTP. The PFBT exhibits quasi reversible oxidation and reduction. However, the electrochemical oxidation of the PFQ and PFTP is not reversible under the experimental conditions. The electrochemical oxidation and reduction potentials and the electronic structure parameters are summarized in Table 3. The HOMO and LUMO levels of the PF are -5.39 and $-2.44 \mathrm{eV}$, respectively. The HOMO levels of the PFQ, PFBT, and PFTP are in the range of -5.13 to $-5.51 \mathrm{eV}$, which are similar to that of the PF. However, the LUMO levels of these alternating copolymers are smaller than that of the PF,

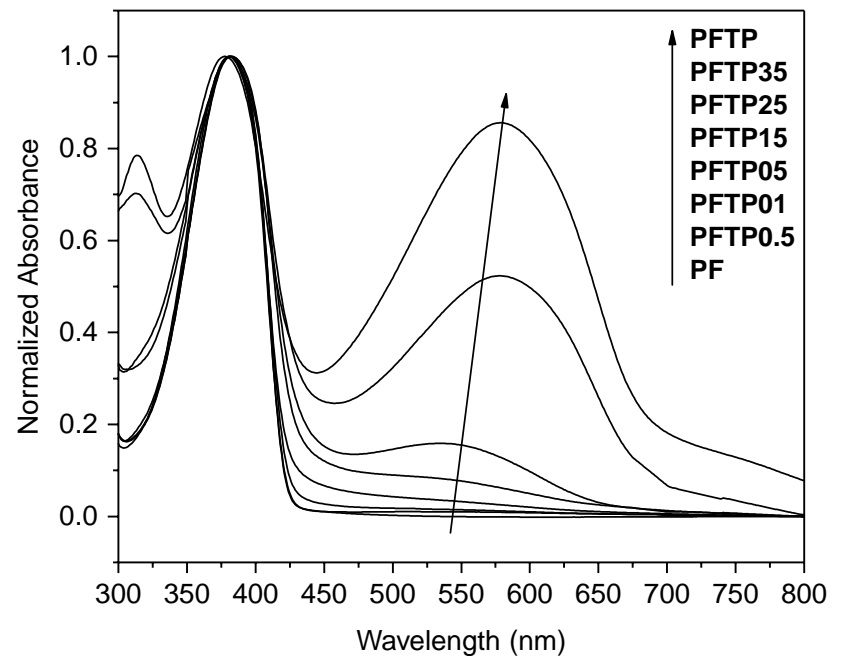

Fig. 4. Normalized UV-vis absorption spectra of the PF, PFTP, and PFTP0.5PFTP35 films on glass substrates. 


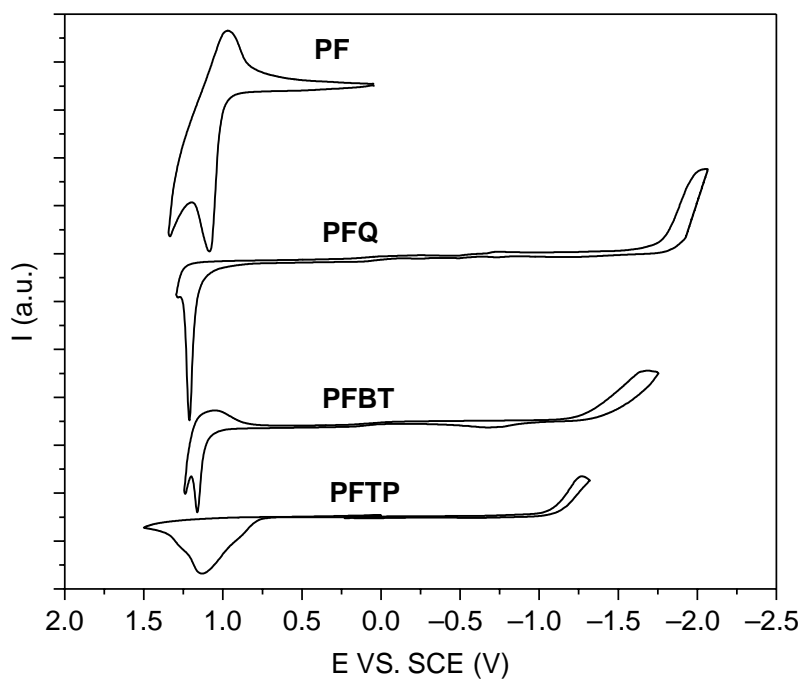

Fig. 5. Cyclic voltammograms of the PF, PFQ, PFBT, and PFTP films on platinum in $\mathrm{M}$ acetonitrile $(99.5+\%$, Tedia) solution containing tetrabutylammonium tetrafluoroborate $\left(\mathrm{TBABF}_{4}\right)($ Fluka, $>99.9 \%)$ as the electrolyte.

which are $-2.65,-3.14$, and $-3.33 \mathrm{eV}$ for the PFQ, PFBT, and PFTP, respectively. It suggests that the incorporation of the acceptor moiety increases the electron affinity. The electrochemical band gaps estimated from the difference of the obtained HOMO and LUMO levels are 2.86, 2.35, and $1.80 \mathrm{eV}$ for PFQ, PFBT, and PFTP, respectively, which has the trend as the optical band gap variation. It also demonstrates the more efficient intramolecular charge transfer of the PFTP than that of the other two polymers. The electrochemical characteristics of PFTP0.5-PFTP35 are summarized in Table 3. The onset oxidation and reduction potentials of the PFTP0.5-PFTP35 vary between 0.73 (PFTP)-0.99 and -1.07 (PFTP) to $-1.34 \mathrm{~V}$, respectively. The HOMO level of the PFTP0.5-PFTP35 does not show a significant variation except that of the PFTP35 with $-5.25 \mathrm{eV}$. The LUMO levels decrease from $-3.07 \mathrm{eV}$ to $-3.33 \mathrm{eV}$ as the $\mathbf{T P}$ content increasing from 0.5 to $50 \%$, which also indicates the incorporation of the acceptor moiety on the polymer backbone.

\subsection{Photoluminescence properties}

Fig. 6 shows the photoluminescence spectra of the PF, PFQ, PFBT, and PFTP in solid-state films excited at the wavelength of $380 \mathrm{~nm}$, of which the corresponding emission maxima $\left(\lambda_{\max }^{\mathrm{PL}}\right)$ are summarized in Table 2 . The $\lambda_{\max }^{\mathrm{PL}}$ of the $\mathbf{P F}$, PFQ, PFBT, and PFTP in THF are 412, 488, 532, and $646 \mathrm{~nm}$, respectively, while those in solid-state films are 445, 493, 540, and $674 \mathrm{~nm}$. The $\lambda_{\max }^{\mathrm{PL}}$ of the PFBT at $2.33 \mathrm{eV}(532 \mathrm{~nm})$ in THF is in good agreement with that at $2.30 \mathrm{eV}$ reported in literature [32]. The variation of emission peaks shows the same trend as that of optical absorption spectra. The emissive colors of the PF, PFQ, PFBT, and PFTP are blue, green, yellow, and red, respectively, which cover the entire visible region. The above results suggest that the color tuning of the fluorene-based alternating copolymers by incorporating different acceptor segments in the backbone is feasible. Two additional emission peaks of the PFTP at 439 and $508 \mathrm{~nm}$ are observed in the solid state but not shown in dilute solution. They are probably attributed to the intermolecular interaction of the fluorene segments and the formation of excimers in the solid state, respectively, as compared to the PL spectrum of the PF

The photoluminescence characteristics of the PFTP in dilute solution (ca. $10^{-6} \mathrm{M}$ ) were investigated in different solutions with increasing solvent polarity of triethylamine (TEA), toluene, THF, $\mathrm{CHCl}_{3}$, and $\mathrm{CHCl}_{3} / \mathrm{CH}_{3} \mathrm{OH}$ (volume ratio=1:1). The corresponding $\lambda_{\max }^{\mathrm{PL}}$ on the above solvents are at $627,633,646,667$, and $678 \mathrm{~nm}$, respectively. It suggests that the $\lambda_{\max }^{\mathrm{PL}}$ could increase up to $51 \mathrm{~nm}$ with increasing the solvent polarity. Such positive solvatochromism indicates a significant intramolecular charge transfer excited in the PFTP [33,34]. Similar phenomena of positive solvatochromism on photoluminescence were also observed in the PFQ and PFBT but with smaller red shifts of 33 and $31 \mathrm{~nm}$, respectively. Hence, it indicates that more efficient intramolecular charge transfer in the PFTP than the other two polymers from the above result.

Fig. 7(a) and (b) shows the photoluminescence spectra of the PF, PFTP, and PFTP0.5-PFTP35 excited at the wavelength of $380 \mathrm{~nm}$ in THF and solid state film,

Table 3

Electrochemical properties of the studied polymers

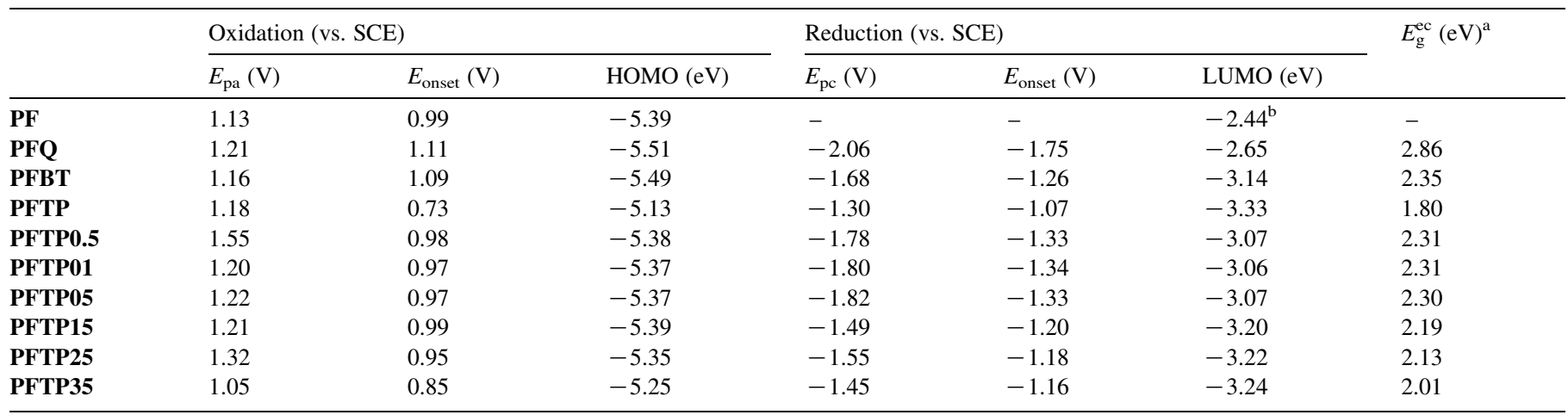

\footnotetext{
a The electrochemical band gap, $E_{\mathrm{g}}^{\mathrm{ec}}=$ LUMO - HOMO.

${ }^{\mathrm{b}}$ Estimated by the relation of LUMO $=E_{\mathrm{g}}^{\mathrm{opt}}+\mathrm{HOMO}$.
} 


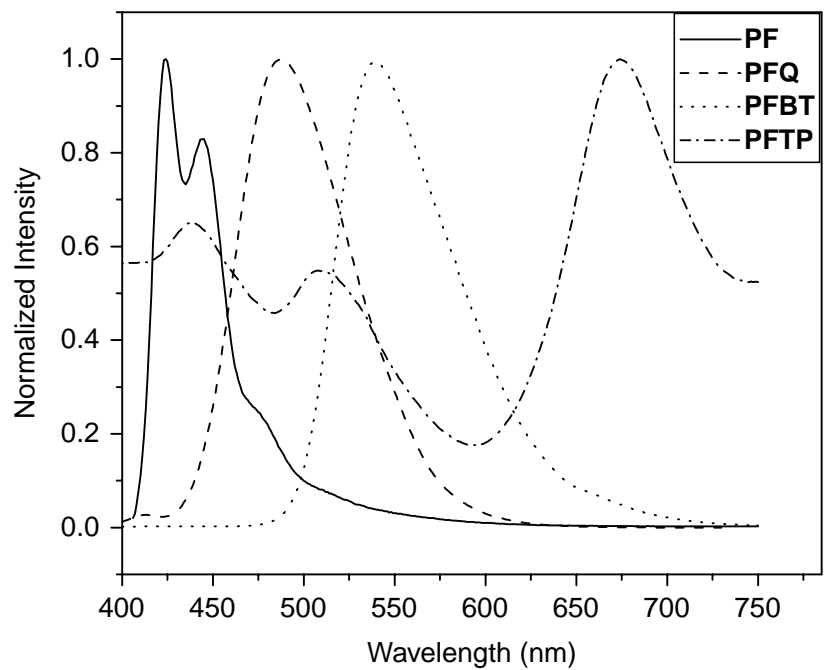

Fig. 6. Normalized PL spectra of the PF, PFQ, PFBT, and PFTP in solid state films.
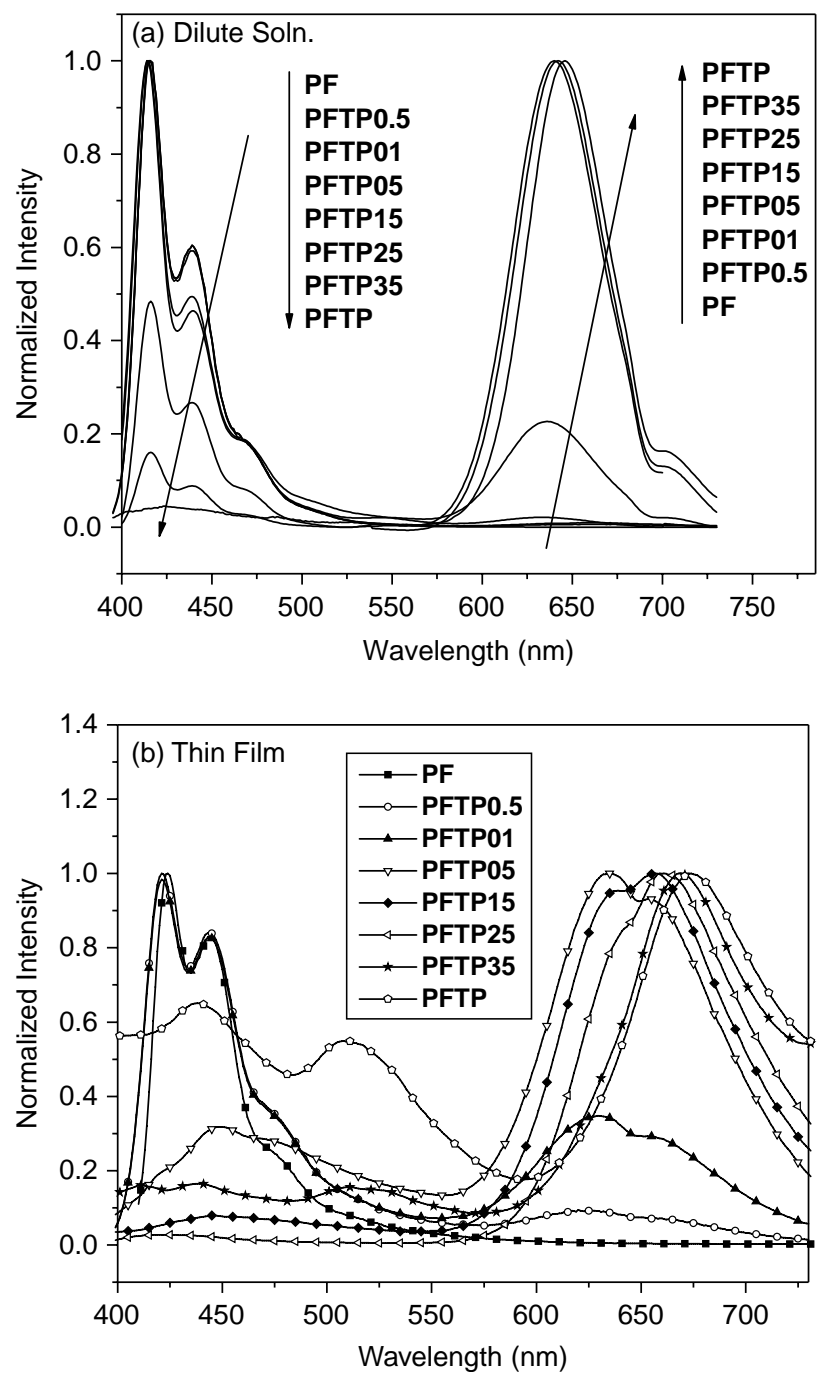

Fig. 7. (a) Normalized PL spectra of the PFTP0.5-PFTP35 in THF (ca. $10^{-6} \mathrm{M}$ ) and (b) solid state films, respectively. respectively, of which the corresponding $\lambda_{\max }^{\mathrm{PL}}$ are summarized in Table 2. As shown in Fig. 7(a), the PL spectra of the PFTP0.5 and PFTP01 in dilute solution are dominated by emission from the $\mathbf{P F}$ segments. As the TP content increases to the PFTP05, a tiny additional emission peak is observed at $634 \mathrm{~nm}$ as compared to that of PF. The intensity of such emission peak increases with increasing the TP content from $5-50 \%$ and undergoes a red shift from 634-646 nm. It indicates that this long-wavelength emission peak is attributed to the TP segment. The increasing intensity of the long-wavelength peak with increasing TP content also suggests that energy transfer from the excited state of the $\mathbf{P F}$ to the TP segments [19]. This energy transfer was also observed in similar systems of fluorene with different comonomers, including 2,1,3-benzoselenadiazole, 4,7-di-2'-thienyl-2,1,3-benzothiadiazole, 2,1,3naphtho-selenadizole, 4,7-di( $2^{\prime}$-selenophenyl)-2,1,3-benzothiadiazole, and 4,7-di(2'-selenophenyl)-2,1,3benzoselenadiazole, in the literatures [19,35-37]. The PL spectra of the PF, PFTP, and PFTP0.5-PFTP35 films shown in Fig. 7(b) also exhibit two emission peaks around 430 and $640 \mathrm{~nm}$, corresponding to the PF and TP segments, respectively. As compared to Fig. 7(a), the long-wavelength emission peaks of these polymer films undergo a red shift for 1-28 nm from those in THF. The long-wavelength peak at $620 \mathrm{~nm}$ is observed at the relatively low TP content of $0.5 \%$ in solid state, in comparison with the absence of this peak of FTP0.5 in dilute solution. It indicates that interchain energy transfer plays an important role in solid state. The relative intensities of the longwavelength to short-wavelength emission peak in Fig. 7(b) increases first from PFTP0.5 to PFTP25 and then decreases with increasing TP content. The PL characteristics of these copolymers in solid state could be influenced by two competing effects: Förster energy transfer and the intramolecular charge transfer/heavy-atom fluorescence quenching. As increasing the TP content, it increases the energy transfer from the PF to TP segments and results in an enhancement of the longwavelength peak. However, the fluorescence quenching due to the intramolecular charge transfer/heavy-atom effect arisen from TP segments also becomes more pronounced as the TP content larger than $35 \%$.

The energy transfer between the $\mathbf{P F}$ and $\mathbf{T P}$ segments was further studied by the PL spectra of the PFTP15 in THF with different concentrations of $5 \times 10^{-7}-1 \times 10^{-4} \mathrm{M}$, as shown in Fig. 8. Even in a very dilute concentration of $5 \times 10^{-7} \mathrm{M}$ (low enough to avoid a strong interchain energy transfer), the longwavelength emission peak contributed by the TP segment could be observed. It indicates relatively efficient intrachain energy transfer between $\mathbf{P F}$ and $\mathbf{T P}$ segment. The relative intensities of the long-wavelength to short-wavelength emission peak increase with increasing solution concentration. The short-wavelength emission peak contributed by the $\mathbf{P F}$ segments is completely quenched when the concentration is equal to or greater than $5 \times 10^{-5} \mathrm{M}$. This suggests that the energy transfer between $\mathbf{P F}$ and $\mathbf{T P}$ segments also happens via interchain mechanism.

Table 2 also lists the PL efficiencies of the studied polymer films. The PL efficiencies of the PF, PFQ, PFBT, and PFTP 


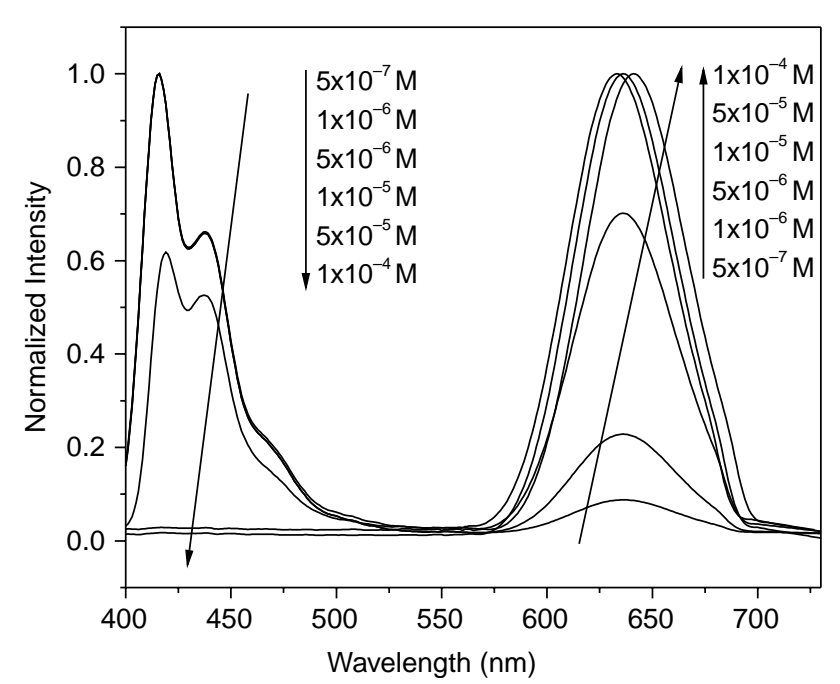

Fig. 8. Normalized PL spectra of the PFTP15 in THF solution with different concentrations of $5 \times 10^{-7}-1 \times 10^{-4} \mathrm{M}$.

are 56.6, 22.4, 18.5, and 2,1\%, respectively. The PL efficiency shows a dramatic decrease after the incorporation of acceptor segments on the backbone. It suggests that the PL efficiencies decrease by increasing intramolecular charge transfer, which is similar to those reported in the literature [33,38]. Another possibility of the poor PL efficiencies on the PFTP could also be attributed to the heavy-atom effect of the sulfur on the thiophene ring, which increases the intersystem crossing of singlet and triplet which results in the loss of PL efficiency [16]. The PL efficiencies of the random copolymers, PFTP0.5PFTP35 also decrease with increasing the TP content on the main chain but higher than the alternating copolymer, PFTP due to the reducing intramolecular charge transfer or heavyatom effect. Similar variation on the PL efficiencies was also observed for the copolymers derived from 9,9-dioxylfluorene and 4,7-di-2'-thienyl-2,1,3-benzothiadiazole [35]. The higher PL efficiencies of random copolymers than those of alternating copolymers suggest that the incorporation of very small amount of acceptor is more favorable in consideration of efficient light-emitting device applications.

\subsection{Electroluminescence (el) characteristics}

EL devices with the studied polymers as emissive layers were fabricated with configuration ITO/PEDOT:PSS/emissive layer/Ca/Ag. Fig. 9 shows the EL spectra of the EL devices with the PF, PFQ, and PFBT as the emissive layer, respectively. The emission maxima $\left(\lambda \frac{\mathrm{max}}{\mathrm{EL}}\right)$ of $\mathrm{EL}$ devices based on the PF, PFQ, and PFBT are 425, 480, and $540 \mathrm{~nm}$, respectively, which are similar to the corresponding $\lambda_{\max }^{\mathrm{PL}}$ shown in Fig. 6. This result suggests that the color tuning on the EL devices of polyfluorenes through incorporation various acceptors on the backbone is feasible. However, the EL device with the PFTP as the emissive layer was too weak to be detected. It is probably due to the intramolecular charge transfer or heavy-atom effect resulting in fluorescence quenching as described previously. Fig. 10 shows the EL spectra using the random copolymers of PFTP0.5-PFTP25 as the emissive

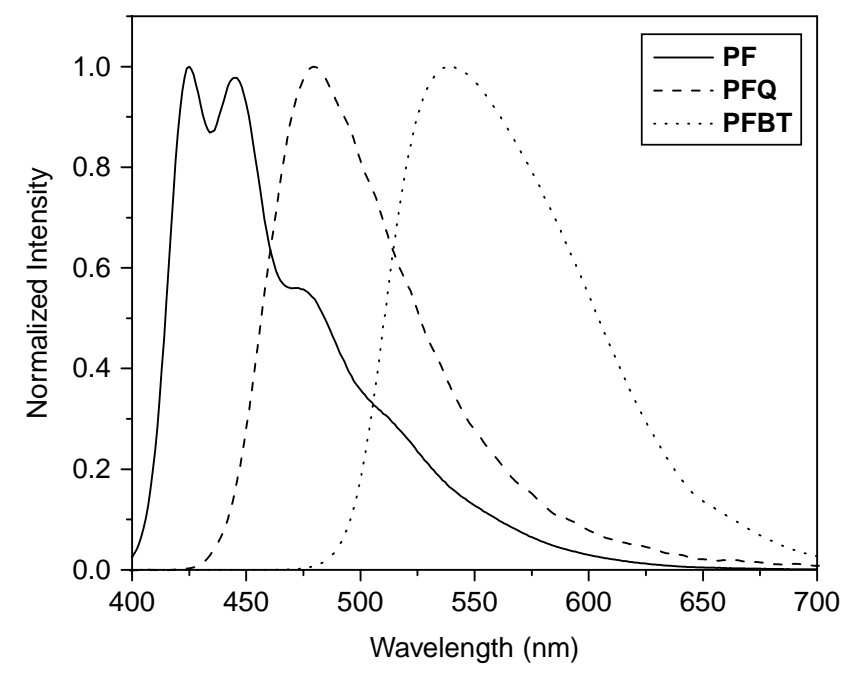

Fig. 9. EL spectra using the PF, PFQ, and PFBT as the emissive layer.

layer. The EL device with the PFTP35 as emissive layer is too weak to be detected, which is attributed to the same reason in the case of the PFTP. As shown in the figure, the emission maxima are red-shifted from $632 \mathrm{~nm}$ of the PFTP0.5 to $667 \mathrm{~nm}$ of the PFTP25. Besides, only red emission is observed in the EL spectra as the TP content greater than $1 \%$, which is quite different from the corresponding PL spectra. Even for the EL device based on the PFTP0.5, the red emission from the TP segment is stronger than the blue emission from PF segment. The differences between the PL and EL spectra could be attributed to the differences in the recombination zone for photo- and electric excitations [39]. For the case of the PL, red emission arises from the Förster energy transfer from PF segment to TP segment. However, the dominant red emission in EL arises from the charge trapping mechanism. The TP segment serves as an efficient electron trap, and the generated excitons are efficiently confined on TP segment. Therefore, blue emission are completely quenched even the TP content as

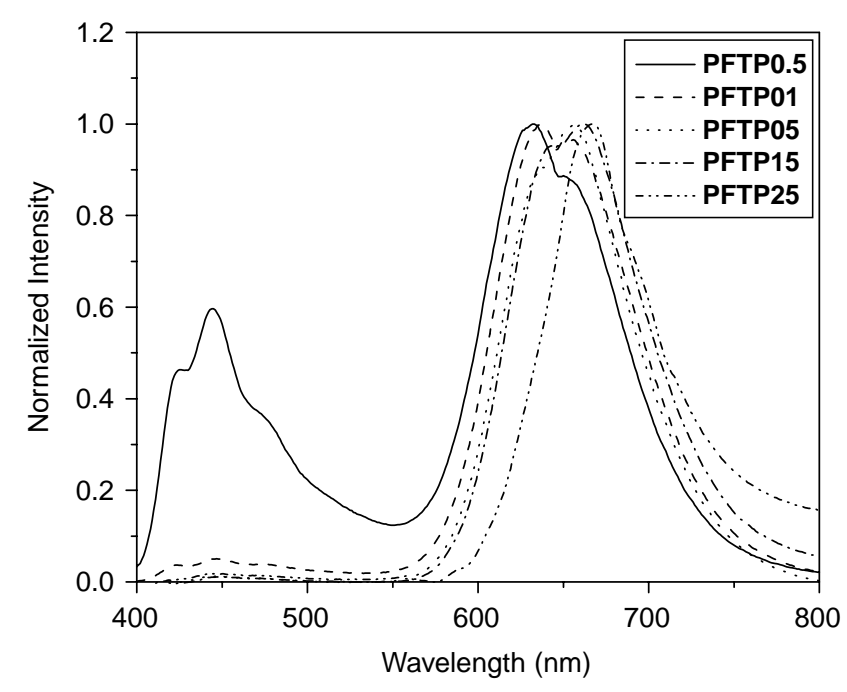

Fig. 10. EL spectra using the PFTP0.5-PFTP25 as the emissive layer. 
Table 4

Luminescence characteristics of the studied polymers

\begin{tabular}{|c|c|c|c|c|c|c|c|c|}
\hline & \multirow{2}{*}{$\lambda_{\max }^{\mathrm{EL}}(\mathrm{nm})$} & \multirow[t]{2}{*}{$\operatorname{Bias}(\mathrm{V})$} & \multirow{2}{*}{$\begin{array}{l}\text { Current density } \\
\left(\mathrm{mA} / \mathrm{cm}^{2}\right)\end{array}$} & \multirow{2}{*}{$\begin{array}{l}\text { Luminance } \\
\left(\mathrm{cd} / \mathrm{m}^{2}\right)\end{array}$} & \multirow{2}{*}{$\begin{array}{l}\text { Luminance } \\
\text { yield (cd/A) }\end{array}$} & \multirow[t]{2}{*}{$\mathrm{EQE}_{\max }(\%)$} & \multicolumn{2}{|c|}{ Chromaticity coordinate } \\
\hline & & & & & & & $x$ & $y$ \\
\hline PF & $425,445,475$ & 10.5 & 54.7 & 103 & 0.188 & 0.18 & 0.221 & 0.264 \\
\hline PFQ & 480 & 8.5 & 24.5 & 93.3 & 0.381 & 0.20 & 0.228 & 0.397 \\
\hline PFBT & 540 & 7 & 58.1 & 623 & 1.07 & 0.13 & 0.430 & 0.559 \\
\hline PFTP & N/A & N/A & N/A & N/A & N/A & N/A & N/A & N/A \\
\hline PFTP0.5 & $425,445,632$ & 12 & 39.9 & 61.1 & 0.153 & 0.14 & 0.545 & 0.302 \\
\hline PFTP01 & 638 & 12.5 & 43.8 & 175 & 0.399 & 0.48 & 0.660 & 0.312 \\
\hline PFTP05 & 656 & 14 & 28.6 & 18.9 & 0.066 & 0.08 & 0.659 & 0.317 \\
\hline PFTP15 & 662 & 12 & 29.4 & 10.2 & 0.035 & 0.04 & 0.664 & 0.320 \\
\hline PFTP25 & 667 & 10.5 & 24.3 & 6.3 & 0.026 & 0.03 & 0.701 & 0.299 \\
\hline PFTP35 & N/A & N/A & N/A & N/A & N/A & N/A & N/A & N/A \\
\hline
\end{tabular}

Device structure: ITO/PEDOT:PSS/emissive layer/Ca/Ag. Measured at maximum luminance yield.

a Active area is $0.1256 \mathrm{~cm}^{2}$.

b The commission Internationale de L'Eclairage (CIE) 1931 coordinates.

low as $1 \%$. It has been shown for the intramolecular trapping systems [19] that the hole and electron trapping mechanism is most favorable if the HOMO level of the guest is above that of the host and if LUMO level of the guest is below that of host [40]. As discussed in the electrochemical characteristics, the HOMO levels of the PFTP0.5-PFTP25 is almost the same as that of the PF but the LUMO levels are lower. Therefore, electron trapping is highly favorable in the EL devices based on the PFTP0.5-PFTP25.

Table 4 lists the EL characteristics using the studied polymers as emissive layer. The external quantum efficiency (EQE) of the PF, PFQ, and PFBT are 0.18, 0.20, and 0.13\%, respectively, which shows a different trend with the corresponding PL efficiencies of 56.6, 22.4, and 18.5\%. It has been discussed previously that the PL efficiency may decrease with increasing intramolecular charge transfer between fluorene and acceptor segments. However, the EQE of the PFQ is greater than that of the PF. It is probably attributed to the LUMO levels of the PFQ $(-2.65 \mathrm{eV})$ and PF $(-2.44 \mathrm{eV})$ compared with the work function of the calcium cathode $(2.87 \mathrm{eV})$. The lower the LUMO level, the smaller electron-injection barrier lays between the emissive layer and calcium cathode, which results in a higher EQE of PFQ. For the EL characteristics based on the PFTP0.5-PFTP25, there are two competing factors for the variation of EQE: the LUMO level and intramolecular charge transfer or heavy-atom effect. The EQE increases first from $0.14-0.48 \%$ as the TP content increases from $0.5-1 \%$ but then decrease rapidly at a higher TP content. As mentioned in the previous section, both fluorescence quenching due to intramolecular charge transfer or heavy-atom effect lower the PL efficiencies of these copolymers with increasing $\mathbf{T P}$ content. However, the TP segment could lower the LUMO level and facilitate electron transporting. The LUMO level decreases from -3.07 to $-3.33 \mathrm{eV}$ as $\mathbf{T P}$ content increasing from $0.5-35 \%$, which results in decreasing electron-injection barrier with increasing TP content. These two competing effects result in an optimum EQE using FTP01 as emissive layer. Nevertheless, the better
$\mathrm{EQE}$ of the fluorene-TP random copolymers than that of the FTP alternating copolymer suggest that color tuning and enhanced device performance could be accomplished with incorporating a very small amount of acceptor on the backbone. The commission Internationale de L'Eclairage (CIE) 1931 coordinates of the LEDs with PFQ, PFBT, and PFTP01 as emissive layers under the condition of maximum EQE are $(0.228,0.397),(0.430,0.559)$, and $(0.660,0.312)$, respectively. The standard red and green demanded by the National Television System Committee (NTSC) are (0.66, $0.34)$ and $(0.26,0.65)$, respectively. The emissive color of PFTP01 is almost identical to the standard red demanded by the NTSC. However, the emissive color of PFQ is blue-green rather than the standard green demanded by the NTSC. Further modification of acceptor strength will be required to fulfill the standard green emission. Nevertheless, the emission maxima as well as the CIE coordinates listed in Table 4 suggest the successful color tuning of fluorene-based donor-acceptor copolymers by incorporation of different acceptor segments.

\section{Conclusions}

Three fluorene-acceptor alternating copolymers (PFQ, PFBT, PFTP) and six fluorene-TP (PFTP0.5-PFTP35) random copolymers were prepared and characterized. The experimental results suggest that the acceptor strength or content significantly affect the electronic and optoelectronic properties due to the acceptor strength or intramolecular charge transfer, including the optical band gap, LUMO level, and luminescence maximum. The emission maxima of the photoluminescence spectra on the PF, PFQ, PFBT, and PFTP films corresponding to the color of blue, green, yellow, and red, respectively. The significant positive solvatochromism on the PL spectra in different polar solvents suggests that the efficient intramolecular charge transfer in PFTP. However, such charge transfer or heavy-atom effect results in fluorescence quenching and thus reduces the PL efficiencies. By random copolymerizing the $\mathbf{T P}$ into the $\mathbf{P F}$, the PL efficiency 
could be improved. A significantly reduction on the PF emission peak with increasing the TP content of the PFTP0.5PFTP35 suggests the energy transfer between the PF and TP segments. Besides, the characteristics of the electroluminescence devices suggest that such energy transfer results in the complete quenching of the PF emission as only $1 \% \mathbf{T P}$ content (PFTP01). The maximum external quantum efficiency (EQE) of the EL device based on the PFTP01 is superior to that of the PF due to a better matching of the LUMO level with the calcium cathode. The CIE 1931 coordinates of the PFTP01 based EL devices under the condition of maximum EQE is $(0.66,0.31)$, which is close to the standard red of $(0.66,0.34)$. The luminescence characteristics based on the prepared polymers depend on the Förster energy transfer or the intramolecular charge transfer, or heavy-atom fluorescence quenching. The present study suggests that the tuning of the electronic and optoelectronic properties could be achieved by incorporating various acceptors or content into the polyfluorenes.

\section{Acknowledgements}

This work was supported by the National Science Council and the Ministry of Economic Affairs of Taiwan, ROC. We thank Mr Yi-Chih Tung for the technical assistance for preparing the PFQ sample.

\section{References}

[1] Burroughes JH, Bradley DDC, Brown AR, Marks RN, Mackay K, Friend RH, et al. Nature 1990;347:539.

[2] Kraft A, Grimsdale AC, Holmes AB. Angew Chem, Int Ed 1998;37:402.

[3] Halls JJM, Walsh CA, Greenham NC, Marseglia EA, Friend RH, Moratti SC, et al. Nature 1995;376:498.

[4] Yu G, Gao J, Hummelen JC, Wudl F, Heeger AJ. Science 1995;270:1789.

[5] Yang Y, Heeger AJ. Nature 1994;372:344.

[6] Sirringhaus H, Tessler N, Friend RH. Science 1998;280:1741.

[7] Babel A, Jenekhe SA. J Am Chem Soc 2003;125:13656.

[8] van Mullekom HAM, Vekemans JAJM, Havinga EE, Meijer EW. Mater Sci Eng 2001;32:1.

[9] Bredas JL, Heeger AJ, Wudl F. J Chem Phys 1986;85:4673.
[10] Banister AJ, Gorrel IB. Adv Mater 1998;10:1415.

[11] Yamamoto T, Zhou Z-H, Kanbara T, Shimura M, Kizu K, Maruyama T, et al. J Am Chem Soc 1996;118:10389.

[12] Akoudad S, Roncali J. Chem Commun 1998;2081.

[13] Zhang X, Jenekhe SA. Macromolecules 2000;33:2069.

[14] Liu CC, Tsai FC, Chang CC, Hsieh KH, Lin JJ, Chen WC. Polymer 2005; 46:4950.

[15] Lin WJ, Chen WC, Wu WC, Niu YH, Jen AKY. Macromolecules 2004; 37:2335.

[16] Herguth P, Jiang X, Liu MS, Jen AKY. Macromolecules 2002;35:6094.

[17] Liu SP, Chan HSO, Ng SC. J Polym Sci, A: Polym Chem 2004;42:4792.

[18] Kinder L, Kanicki J, Petroff P. Synth Met 2004;146:181.

[19] Yang J, Jiang C, Zhang Y, Yang R, Yang W, Hou Q, et al. Macromolecules 2004;37:1211.

[20] Sonar P, Zhang J, Grimsdale AC, Müllen K, Surin M, Lazzaroni R, et al. Macromolecules 2004;37:709.

[21] Kulkarni AP, Zhu Y, Jenekhe SA. Macromolecules 2005;38:1553.

[22] Ego C, Marsitzky D, Becker S, Zhang J, Grimsdale AC, Müllen K, et al. J Am Chem Soc 2004;125:437.

[23] Snaith HJ, Greenham NG, Friend RH. Adv Mater 2004;16:1640.

[24] Chua L-L, Zaumseil J, Chang J-F, Ou EC-W, Ho PK-H, Sirringhaus H, et al. Nature 2005;434:194.

[25] Kitamura C, Tanaka S, Yamashita Y. Chem Mater 1996;8:570.

[26] Pilgram K, Zupon M, Skiles RJ. Heterocycl Chem 1970;7:629.

[27] Naef R, Balli H. Helv Chim Acta 1978;61:2958.

[28] Yamamoto T, Sugiyama K, Kushida T, Inoue T, Kanbara T. J Am Chem Soc 1996;118:3930.

[29] Kenning DD, Mitchell KA, Calhoun TR, Funfar MR, Sattler DJ, Rasmussen SC. J Org Chem 2002;67:9073.

[30] Berlin A, Zanelli A. Chem Mater 2004;16:3667.

[31] Tsai FC, Chang CC, Liu CL, Chen WC, Jenekhe SA. Macromolecules 2005;38:1958.

[32] Campbell AJ, Bradley DDC, Antoniadis H. Appl Phys Lett 2001;79:2133.

[33] Jenekhe SA, Lu L, Alam MM. Macromolecules 2001;34:7315.

[34] Reichardt C. Chem Rev 1994;94:2319.

[35] Hou Q, Xu Y, Yang W, Yuan M, Peng J, Cao Y. J Mater Chem 2002;12: 2887.

[36] Yang R, Tian R, Hou Q, Yang W, Cao Y. Macromolecules 2003;36: 7453.

[37] Yang R, Tian R, Yan J, Zhang Y, Yang J, Hou Q, et al. Macromolecules 2005;38:244.

[38] Zhang QT, Tour JM. J Am Chem Soc 1998;120:5355.

[39] McGehee MD, Bergstedt TT, Zhang C, Saab AP, O'Regan MB, Bazan GC, et al. Adv Mater 1999;11:1349.

[40] Gong X, Ostrowski JC, Moses D, Bazan GC, Heeger AJ. Adv Funct Mater 2003;13:439. 